\title{
BMJ Open A cross-sectional study of predatory publishing emails received by career development grant awardees
}

\author{
Tracey A Wilkinson, ${ }^{1}$ Christopher J Russell, ${ }^{2,3}$ William E Bennett, ${ }^{4}$ Erika R Cheng, ${ }^{1}$ \\ Aaron E Carroll ${ }^{5}$
}

To cite: Wilkinson TA, Russell CJ, Bennett WE, et al. A cross-sectional study of predatory publishing emails received by career development grant awardees. BMJ Open 2019;9:e027928. doi:10.1136/ bmjopen-2018-027928

- Prepublication history for this paper is available online. To view these files, please visit the journal online (http://dx.doi org/10.1136/bmjopen-2018027928).

Received 14 November 2018 Revised 18 April 2019 Accepted 24 April 2019

Check for updates

(C) Author(s) (or their employer(s)) 2019. Re-use permitted under CC BY-NC. No commercial re-use. See rights and permissions. Published by BMJ.

${ }^{1}$ Children's Health Services Research, Indiana University Department of Pediatrics, Indianapolis, Indiana, USA

2Division of Hospital Medicine, Children's Hospital of Los Angeles, Los Angeles, California, USA

${ }^{3}$ Department of Pediatrics, Keck School of Medicine of the University of Southern California, Los Angeles, California, USA

${ }^{4}$ Division of Gastroenterology, Department of Pediatrics, Indiana University School of Medicine, Indianapolis, Indiana, USA

${ }^{5}$ Department of Pediatrics, Indiana University, Indianapolis, Indiana, USA

Correspondence to

Dr Tracey A Wilkinson;

tracwilk@iu.edu

\section{ABSTRACT}

Objective To investigate the scope of academic spam emails (ASEs) among career development grant awardees and the factors associated with the amount of time spent addressing them.

Design A cross-sectional survey of career development grant investigators via an anonymous online survey was conducted. In addition to demographic and professional information, we asked investigators to report the number of ASEs received each day, how they determined whether these emails were spam and time they spent per day addressing them. We used bivariate analysis to assess factors associated with the amount of time spent on ASEs. Setting An online survey sent via email on three separate occasions between November and December 2016. Participants All National Institutes of Health career development awardees funded in the 2015 fiscal year. Main outcome measures Factors associated with the amount of time spent addressing ASEs.

Results A total of 3492 surveys were emailed, of which 206 (5.9\%) were returned as undeliverable and 96 (2.7\%) reported an out-of-office message; our overall response rate was $22.3 \%(n=733)$. All respondents reported receiving ASEs, with the majority (54.4\%) receiving between 1 and 10 per day and spending between 1 and 10 min each day evaluating them. The amount of time respondents reported spending on ASEs was associated with the number of peer-reviewed journal articles authored $(p<0.001)$, a history of publishing in open access format $(p<0.01)$, the total number of ASEs received $(p<0.001)$ and a feeling of having missed opportunities due to ignoring these emails $(p=0.04)$.

Conclusions ASEs are a common distraction for career development grantees that may impact faculty productivity. There is an urgent need to mitigate this growing problem.

\section{INTRODUCTION}

In the last 10 years, a subset of 'predatory' publishers has been able to flourish within the $\$ 10.5$ billion per year market. ${ }^{1-4}$ These predatory publishers send unsolicited emails that request manuscript submissions, offer rapid review and use publication fees (rather than traditional peer or editorial review) as criteria to accept articles. ${ }^{5-7}$ As a result of this model, there have been documented instances of accepting flawed

\section{Strengths and limitations of this study}

This is the first study to describe the scope of academic spam emails and factors associated with time spent adressing them among career development grantees.

- The survey was distributed by email; thus, it could have been perceived as a spam email by recipients.

- The survey included only recipients of National Institutes of Health funding and did not include those who have applied for funding and were not successful.

manuscripts or fake editorial board members. ${ }^{8-11}$ Because academic research faculty career success is often centred on their publication and funding record, their ability to obtain funding to conduct research is intimately linked to their success in publishing their work. Junior academic faculty are particularly focused on opportunities to publish, given the importance tied to their promotion. They may, therefore, be most susceptible to academic spam emails (ASEs) from predatory publishers, which contain unsolicited requests for publishing manuscripts, presentations at organisation meetings and memberships on editorial boards.

Previous studies have examined the quantity and quality of predatory publishers, as well as characteristics of authors who publish in them. ${ }^{1012-19}$ However, to our knowledge, no study has described the prevalence of this phenomenon among researchers early in their career or quantified the time spent on ASEs. Therefore, we sought to examine factors associated with the amount of time spent addressing ASEs by career development grantees.

\section{METHODS}

\section{Study design and data source}

We obtained the contact information for all National Institutes of Health (NIH) $\mathrm{K}$ awardees in the fiscal year of 2015 via a Freedom of Information Act request. 
Information of federal grant awardees is a standard report issued by the NIH Freedom of Information Office that is available online. ${ }^{20}$ We then created and emailed an online survey using Survey Monkey, ${ }^{21}$ consisting of 14 questions to the correspondent/recipient on record of each $\mathrm{K}$ award.

The survey was conducted using a self-structured questionnaire, which was piloted among 10 faculty at Indiana University School of Medicine that were not current $\mathrm{K}$ awardees to assure clarity of questions and adequate response options. If a question was not clear or the answer choices were not sufficient, the survey was edited before it was sent to the next faculty member. This process was repeated until there were no additional feedback suggestions. Validity testing on the survey (prior to the surveys being sent to the study participants) was not done. The survey was sent a total of three times over a 2-month period (November-December) in 2016 to 3492 NIH K awardees. The email was generated from a valid, personal email account of one of the study investigators (TAW).

The survey requested information regarding basic demographic (eg, gender) and professional information (eg, academic job title, year of terminal degree and publication history). Survey respondents were also asked several questions about their experience with ASEs, which was described to survey respondents as an 'unsolicited email requesting articles/editorial, conference presentations or editorial membership'. Subsequent questions asked respondents to report the number of ASEs they received daily, how they determined whether these emails were spam, the amount of time spent on these emails, whether their email account had a spam filter and if they ever felt like they missed opportunities due to ignoring these emails.

\section{Data analysis}

We summarised responses to survey questions using descriptive statistics and then assessed factors associated with the daily amount of time spent on these emails (recategorised as none, $1-10 \mathrm{~min}$ and $>10 \mathrm{~min}$ ) using $\chi^{2}$ bivariate analysis. We removed respondents with missing data $(n=68)$ or who replied 'not sure' $(n=4)$ to the question about time spent daily addressing ASEs from the bivariate analysis. Respondents removed from this analysis were less likely to have more than 20 publications but otherwise did not differ from those included in the sample by key study variables. All analysis was done using SAS V.9.4.

\section{Patient and public involvement}

For this study, there was no patient involvement; however, we collected data through a survey of NIH grantees available from a public database. ${ }^{20}$

\section{RESULTS}

A total of 3492 surveys were emailed, of which 206 (5.9\%) were immediately returned as undeliverable; 96 (2.7\%) of these 3286 emails had an out-of-office message automatically in response to the enquiry. Of the emails sent and received successfully, $733(22.3 \%)$ surveys were completed by the end of the study period and were used for final analysis. A slight majority were women $(n=399$, $54.4 \%)$. Over two-thirds $(65.5 \%)$ of the respondents were assistant professors working at an academic centre; most (71.9\%) received their NIH K award funding in the 4 years preceding the survey (table 1 ).

With respect to the number of ASEs received each day, every respondent reported receiving at least one ASE in the previous week (data not shown). Over half (54.5\%) reported receiving between 1 and 10 ASEs per day, 30.6\% reported receiving between 11 and 20 emails per day, and $14.1 \%$ reported receiving more than 20 emails per day (table 1). When asked how much time was spent on these emails in a day, $80 \%$ of the respondents reported spending at least some amount of time during the day addressing these emails, with $63 \%$ of the respondents reporting spending between 1 and $10 \mathrm{~min}$ of their day reading, sorting and determining what to do with potential ASEs. The methods of how they determined an email to be academic spam were diverse, with an unknown journal name being the most frequently described method ( $82 \%$ of the respondents). More than a one-third of the respondents $(31 \%)$ reported that they had responded to an ASE in the past.

On bivariate analysis, when examining variables associated with the amount of time spent on ASEs in a day (table 2), we found that neither gender $(\mathrm{p}=0.37)$ nor academic job title $(\mathrm{p}=0.36)$ was associated with the time spent addressing ASEs. Interestingly, the time spent on emails was also not associated with reporting having a SPAM filter $(\mathrm{p}=0.99)$.

However, there was an inverse association $(p<0.001)$ with the number of academic publications reported and the time spent addressing these emails, such that faculty with fewer publications reported spending more time per day reading potential ASEs and assessing their legitimacy. Among faculty with 10 or fewer publications, $87.5 \%$ spent between 1 and $10 \mathrm{~min}$ assessing these emails compared with those with 11-20 publications (80.8\%) and >20 (56.8\%) publications, respectively. More than a quarter of the respondents with $>20$ publications spent no time assessing these emails compared with $0 \%$ of respondents with fewer publications. There was also an association between the number of potential ASEs received in a day and the time spent on them $(\mathrm{p}<0.001)$. Specifically, respondents who received more than 20 ASEs per day were more likely to report spending more than $10 \mathrm{~min} /$ day on these emails than respondents who received fewer emails.

Finally, we assessed whether respondents felt they might have missed opportunities in the past because they mistakenly assumed legitimate emails were academic spam. We found that respondents who were concerned about missed opportunities were almost twice as likely to spend at least $10 \mathrm{~min}$ of their day assessing these emails 
Table 1 Description of survey respondents*

\begin{tabular}{|c|c|}
\hline Variable & Total n (\%) \\
\hline Total responses & $733(100)$ \\
\hline \multicolumn{2}{|c|}{ Demographics and professional information } \\
\hline \multicolumn{2}{|c|}{ Gender } \\
\hline Female & $399(54.4)$ \\
\hline Male & $322(43.9)$ \\
\hline Other/prefer not to answer & $12(1.6)$ \\
\hline \multicolumn{2}{|l|}{ Academic job title $(n=731)$} \\
\hline Assistant professor & $479(65.5)$ \\
\hline Associate professor & $120(16.4)$ \\
\hline Professor & $49(6.7)$ \\
\hline Non-tenure track & $57(7.8)$ \\
\hline Other & $26(3.6)$ \\
\hline \multicolumn{2}{|c|}{ First year to receive NIH funding $(n=729)$} \\
\hline 2011-2016 & $524(71.9)$ \\
\hline 2010-2000 & $169(23.3)$ \\
\hline Prior to 2000 & $36(4.9)$ \\
\hline \multicolumn{2}{|c|}{ Number of academic publications $(n=732)$} \\
\hline $1-10$ & $55(7.5)$ \\
\hline $11-20$ & $181(24.7)$ \\
\hline$>20$ & $496(67.8)$ \\
\hline
\end{tabular}

Previously published in open access format $(n=730)$

Yes 489 (67.0)

No $195(26.7)$

Not sure $\quad 46$ (6.3)

Year terminal degree was obtained $(n=729)$

2010-2016

$137(18.8)$

2005-2009

$307(42.1)$

2000-2004

$202(27.7)$

Prior to 2000

$83(11.4)$

Spam filter on email $(n=729)$

Yes $651(89.3)$

No 36 (4.9)

Not sure $42(5.8)$

Experience with academic spam emails

Estimated number of academic spam emails/day $(n=724)$

$1-10 \quad 398(54.5)$

$11-20 \quad 223(30.6)$

$>20 \quad 103(14.1)$

Not sure $6(0.8)$

Time spent per day reading/sorting academic spam emails $(n=665)$

\begin{tabular}{lc} 
None, delete them all without reading & $132(19.9)$ \\
$1-10 \mathrm{~min}$ & $419(63.0)$ \\
$11-20 \mathrm{~min}$ & $89(13.4)$ \\
$>20 \mathrm{~min}$ & $21(3.2)$ \\
\hline
\end{tabular}

Continued

\begin{tabular}{lc} 
Table 1 Continued & \\
\hline Variable & Total $\mathbf{n}(\%)$ \\
\hline Not sure & $4(0.6)$ \\
History of responding to academic spam email $(\mathrm{n}=729)$ \\
Yes & $226(31.0)$ \\
No & $503(69.0)$ \\
Concern of missed opportunities $(\mathrm{n}=731)$ & \\
Yes & $58(7.9)$ \\
No & $575(78.7)$ \\
Not sure & $98(13.4)$ \\
Methods used to deem emails academic spam† \\
Consider them all spam & $274(37.4)$ \\
Ask a colleague & $123(16.8)$ \\
Typos in text/name & $398(54.5)$ \\
Don't recognise journal & $601(82.0)$ \\
Address listed is not in the USA & $308(42.0)$ \\
Requesting fee to publish & $313(42.7)$ \\
Consult the Internet & $239(32.6)$
\end{tabular}

*Percentages may not sum to 100 due to rounding; total $n$ differs if a question was left blank.

†Respondents were instructed to select all that apply.

$\mathrm{NIH}$, National Institutes of Health.

than those who were not concerned $(24.3 \%$ vs $12.8 \%$, $\mathrm{p}=0.04$ ).

\section{DISCUSSION}

This study sought to examine the scope of ASEs among NIH career development awardees and factors associated with the amount of daily time spent addressing them. We found that receiving ASEs was pervasive in this population. In fact, everyone who responded to the survey reported receiving academic spam, precluding us from examining demographic and job-related factors associated with the receipt of these emails. In addition, $80 \%$ of the respondents reported using time during their day to address these emails.

We examined demographic and job-related factors in relation to the amount of time respondents spent addressing the emails in any given day. Neither gender, academic rank nor having a spam filter affected the time spent addressing these emails, but faculty with $<20$ publications and who felt like they might be missing opportunities did report spending more time addressing these emails than their counterparts. More than $30 \%$ of the respondents who felt that they might have missed opportunities for publication, presentation or editorial service because they ignored an ASE reported spending more than $10 \mathrm{~min}$ every day reading and sorting academic spam. This suggests that academic faculty who are junior and/or who feel pressure to publish might be most susceptible to these types of predatory solicitations. In 
Table 2 Factors associated with time spent on emails

Time spent on academic spam emails per day (\%)

\begin{tabular}{|c|c|c|c|c|}
\hline & & & & \\
\hline & None & $1-10 \mathrm{~min}$ & $>10 \mathrm{~min}$ & P value \\
\hline \multicolumn{5}{|c|}{ Demographics and professional information } \\
\hline Gender & & & & 0.37 \\
\hline Female & 19.9 & 66.0 & 14.0 & \\
\hline Male & 20.1 & 60.4 & 19.5 & \\
\hline Other/prefer not to answer & 16.7 & 58.3 & 25.0 & \\
\hline \multicolumn{5}{|l|}{ Academic job title } \\
\hline Assistant professor & 19.5 & 65.4 & 15.1 & 0.36 \\
\hline Associate professor & 20.7 & 57.8 & 21.6 & \\
\hline Professor & 28.6 & 51.0 & 20.4 & \\
\hline Non-tenure track & 17.4 & 65.2 & 17.4 & \\
\hline Other & 10.5 & 79.0 & 10.5 & \\
\hline \multicolumn{5}{|c|}{ Number of academic publications } \\
\hline $1-0$ & 0.0 & 87.5 & 12.5 & $<0.001$ \\
\hline $11-20$ & 0.0 & 80.8 & 19.2 & \\
\hline$>20$ & 26.9 & 56.8 & 16.3 & \\
\hline \multicolumn{5}{|c|}{ Previously published in open access format } \\
\hline Yes & 23.7 & 67.5 & 8.9 & 0.01 \\
\hline No & 19.7 & 61.7 & 18.6 & \\
\hline Not sure & 9.3 & 65.1 & 25.6 & \\
\hline \multicolumn{5}{|l|}{ Spam filter on email } \\
\hline No & 19.9 & 63.1 & 17.0 & 0.99 \\
\hline Yes & 20.7 & 65.5 & 13.8 & \\
\hline Not sure & 20.0 & 65.0 & 15.0 & \\
\hline \multicolumn{5}{|c|}{ Experience with academic spam emails } \\
\hline \multicolumn{5}{|c|}{$\begin{array}{l}\text { Estimated number of academic spam emails } \\
\text { per day }\end{array}$} \\
\hline $1-10$ & 20.3 & 72.9 & 6.8 & $<0.001$ \\
\hline $11-20$ & 20.3 & 58.0 & 21.7 & \\
\hline$>20$ & 18.6 & 40.2 & 41.2 & \\
\hline Not sure & 0.0 & 100.0 & 0.0 & \\
\hline \multicolumn{5}{|c|}{ Concern for missed opportunities } \\
\hline No & 21.3 & 63.8 & 14.9 & 0.04 \\
\hline Yes & 14.3 & 55.4 & 30.4 & \\
\hline Not sure & 15.9 & 65.9 & 18.2 & \\
\hline
\end{tabular}

addition, the more ASEs received in a day was associated with more time spent addressing them.

While our study was focused on career development grantees who are generally in the early stages of their career, the burden of ASEs is not limited to these faculty. In 2017, a study found that even senior faculty are affected by ASEs, making the case that efforts to control this phenomenon are needed throughout academia. ${ }^{16}$ Therefore, whatever interventions or efforts are undertaken to combat this problem will need to include faculty at all stages and not just new or junior faculty.
As the number of journals and publishers continue to rise, we can expect the number of emails to do so as well. Given the focus of faculty to publish, it is likely that they will continue to spend time reading these emails to determine whether they are legitimate or not, when they could be working on projects, manuscripts and grant proposals. Knowing that ASEs will likely not stop may indicate that faculty should be given an additional piece of training and resources to determine whether or not to respond to unsolicited emails or any easy way to report them to help identify the senders as spam in the future. 
Academic institutions could decide to value publications in predatory journals differently (in terms of promotion criteria) and thus deter faculty from pursuing those opportunities, although that could be viewed as impacting academic freedom. ${ }^{22}$ Additional research exploring how pervasive publication within these journals is occurring among academicians is under way; however, the larger question of how academia will perceive and evaluate these publications within the promotion and tenure setting is yet to be answered..$^{23-25}$

Our study has some limitations. First, we used the contact information for grant awardees provided by the NIH and did not determine individual contact information based on awardees' names and institutions separately. Thus, some email addresses were not working or valid at the time of our survey and may have represented an institutional contact and not the awardee themselves. Furthermore, our study sample was those with funded NIH grants, not including those that may have applied but were not funded. Second, there is a chance that our emailed survey was viewed by recipients as spam itself and was possibly ignored or deleted without a response. We used a valid personal email address with a survey link in the body of the email to solicit respondents, but that also prohibited us from knowing who had completed the survey already or who to follow-up with directly for not completing the survey. Third, the overall response rate was $22 \%$, and we did not require any question on the survey to be answered and thus had some missing data. However, respondents removed from the sample for missing data did not systematically differ from those included, except that they reported having fewer publications. This likely produced conservative results in our bivariate analysis.

Nonetheless, our study quantifies the burden of time faculty spend addressing ASEs as career development grantees and can provide groundwork for further studies examining the burden of ASEs among faculty. There are efforts under way to help researchers choose the right journal for their research, which includes deciphering predatory journals from others. ${ }^{18} 24$ 26-31 Furthermore, efforts at the university level to help improve email filters to block unsolicited emails can be refined and improved, given a majority of our respondents had spam filters in place that permitted these emails to be delivered. This may present challenges as to how to discern ASEs from other emails; however, certain patterns to emails or sender addresses could be used to flag these within a larger system. From a larger system perspective, the publishing industry can build on their current communications to help differentiate from predatory journals for the receivers.

Acknowledgements We would like to thank all the investigators who responded to this survey and academic librarian Jeffrey Beall, who helped with the concept of this study.

Contributors TAW conceptualised and designed the study, distributed the survey, drafted the initial manuscript and approved the final manuscript as submitted. CJR and WEB conceptualised and designed the study and approved the final manuscript as submitted. ERC conceptualised and designed the study, carried out the analysis and approved the final manuscript as submitted. AEC contributed to the study design and data collection, reviewed and revised the manuscript, and approved of the final manuscript as submitted.

Funding The authors have not declared a specific grant for this research from any funding agency in the public, commercial or not-for-profit sectors.

Competing interests None declared.

Patient consent for publication Not required.

Ethics approval The Indiana University Institutional Review Board approved this study with a waiver of consent due to the lack of identifiable information being obtained in the anonymous survey responses.

Provenance and peer review Not commissioned; externally peer reviewed.

Data sharing statement The survey, statistical code and dataset are available by request to the corresponding author, TAW.

Open access This is an open access article distributed in accordance with the Creative Commons Attribution Non Commercial (CC BY-NC 4.0) license, which permits others to distribute, remix, adapt, build upon this work non-commercially, and license their derivative works on different terms, provided the original work is properly cited, appropriate credit is given, any changes made indicated, and the use is non-commercial. See: http://creativecommons.org/licenses/by-nc/4.0/.

\section{REFERENCES}

1. Esposito P. The size of the open access market. The Scholarly Kitchen 2014. http://scholarlykitchen.sspnet.org/2014/10/29/thesize-of-the-open-access-market

2. Shen C, Björk BC. 'Predatory' open access: a longitudinal study of article volumes and market characteristics. BMC Med 2015;13:230.

3. Eriksson S, Helgesson G. The false academy: predatory publishing in science and bioethics. Med Health Care Philos 2017;20:163-70.

4. Gasparyan AY, Yessirkepov M, Diyanova SN, et al. Publishing Ethics and Predatory Practices: A Dilemma for All Stakeholders of Science Communication. J Korean Med Sci 2015;30:1010-6.

5. Cobey KD, Lalu MM, Skidmore B, et al. What is a predatory journal? A scoping review. F1000Res 2018;7:1001.

6. Beall J. Criteria for determining predatory open-access publishers. 2nd edn. Denver, CO: Scholarly Open Access, 2012. http:// scholarlyoa.files.wordpress.com/2012/11/criteria-2012-2.pdf

7. Beall J. Predatory publishers are corrupting open access. Nature 2012;489:179.

8. Daivs P. Open Access Publisher Accepts Nonsense Manuscript for Dollars. 2009. https://scholarlykitchen.sspnet.org/2009/06/10/ nonsense-for-dollars/

9. Butler D. Investigating journals: The dark side of publishing. Nature 2013;495:433-5.

10. Sorokowski P, Kulczycki E, Sorokowska A, et al. Predatory journals recruit fake editor. Nature 2017;543:481-3.

11. Bohannon J. Who's afraid of peer review? Science 2013;342:60-5.

12. Ezinwa Nwagwu W, Ojemeni O. Penetration of Nigerian predatory biomedical open access journals 2007-2012: a bibiliometric study. Learn Publ 2015;28:23-34.

13. Xia J. Predatory journals and their article publishing charges. Learn Publ 2015;28:69-74.

14. Xia J, Harmon JL, Connolly KG, et al. Who publishes in "predatory" journals? J Assoc Inf Sci Technol 2015;66:1406-17.

15. Tin L, Ivana B, Biljana B, et al. Predatory and fake scientific journals/ publishers-a global outbreak with rising trend: a review. Geographica Pannonica 2014;18:69-81.

16. Cobey K. Illegitimate journals scam even senior scientists. Nature 2017;549:7.

17. Bolshete P. Analysis of thirteen predatory publishers: a trap for eagerto-publish researchers. Curr Med Res Opin 2018;34:157-62.

18. Memon AR. Predatory Journals Spamming for Publications: What Should Researchers Do? Sci Eng Ethics 2018;24:1617-39.

19. Shamseer L, Moher D, Maduekwe O, et al. Potential predatory and legitimate biomedical journals: can you tell the difference? A crosssectional comparison. BMC Med 2017;15:28.

20. Contact Information NIH-Supported PIs. National Institutes of Health-Freedom of Information Act Office. 2015.

21. SurveyMonkey, Inc. San Mateo, California, USA.

22. Nelson C. Open Access and Academic Freedom: Inside Higher Ed. 2013. https://www.insidehighered.com/views/2013/11/15/essayimpact-open-access-requirements-academic-freedom 
23. Pyne D. The Rewards of Predatory Publications at a Small Business School. J Sch Publ 2017;48:137-60.

24. Eriksson S, Helgesson G. Time to stop talking about 'predatory journals'. Learn Publ 2018;31:181-3.

25. Memon AR. Publish or perish: A sign of caution for authors to avoid predatory journals. J Pak Med Assoc 2017;67:822.

26. Beall J. Best practices for scholarly authors in the age of predatory journals. Ann R Coll Surg Engl 2016;98:77-9.

27. Laine $C$, Winker MA. Identifying predatory or pseudo-journals. Biochem Med 2017;27:285-91.
28. Memon AR. Research publications and education in Pakistani medical universities: Avoiding predatory journals and improving the quality of research. J Pak Med Assoc 2017;67:830-3.

29. Teixeira da Silva JA, Tsigaris P. What Value Do Journal Whitelists and Blacklists Have in Academia? J Acad Libr 2018;44:781-92.

30. Memon AR. How to respond to and what to do for papers published in predatory journals? Sci Ed 2018;5:146-9.

31. Memon AR. ResearchGate and Impact Factor: A step further on predatory journals. J Pak Med Assoc 2017;67:148-9. 